\title{
Characterization of beach sedimentary environments in the Batinah Region, Oman.
}

\begin{abstract}
In this study, 252 surface sediment samples were collected for sand properties from three sites on the North Batinah coast: Harmul, North of Sohar industrial area, Majees South of Sohar industrial area and Zafaran $9 \mathrm{~km}$ South of Majees. Sampling was conducted in four occasions: November 2005, February 2006, June 2006 and November 2006. Almost, 52\% of all samples were unimodal, 32\% were bimodal and 16\% were polymodal. June 2006 samples had a higher particle density than November 2006 samples. This is most probably due to rework and suspension, which lead to removal of light particles from the upper layer of the beach and high density particles to be concentrated in the bottom layer in June 2006 and deposition of light fraction of lower density in November 2006. Only Harmul samples had a significant difference between June 2006 samples and November 2006 samples in bulk density. The difference between the two sets in percentage water by volume was significant in Harmul and Zafaran but not in Majees. All sites showed significant difference between the two sets in percentage of air filled porosity and percentage of saturation. However, the sand pattern was the same in the three sites.
\end{abstract}

Keyword: Coastal geomorphology; Beach; Sediments. 